\title{
Cloud Computing in Application of University Information Construction
}

\author{
Cuihua Sun ${ }^{1, \text { a }}$, Qifang Guo ${ }^{1, b}$, Zhaoxia Yu ${ }^{1, c}$, Yong Ge, d, Zou Jun ${ }^{1, ~ e, ~ L i a n g ~ X u e ~}{ }^{1, f}$ \\ ${ }^{1}$ Suzhou Polytechnic Institute of Agriculture, Smart Agriculture collage, Suzhou 215008, China \\ ${ }^{2}$ Suzhou Power Supply Company, Smart Agriculture collage, Suzhou 215004, China \\ a39938737@qq.com, ${ }^{b} 510533824 @ q q . c o m,{ }^{c} 106328487 @ q q . c o m,{ }^{d} 373878049 @ q q . c o m,{ }^{e} 7586152$ \\ 1@qq.com, ${ }^{f} 61230374 @ q q . c o m$
}

Keywords: cloud, cloud computing, information construction, university construction

Abstract: Based on the analysis of problem in the university information construction, introduces the concept of cloud computing in the application of university information construction, and proposes the implementation of this application.

\section{Introduction}

As the gathering place of high-quality talents in our country, the construction of campus information develops rapidly. Many universities in China have $1000 \mathrm{MB}$ backbone bandwidth. Some comprehensive colleges and universities have upgraded to 10,000 MB campus network. However, due to the different needs of departments or branches for information collection and processing, different management needs to be established[1]. Information system includes financial management system, educational administration management system and management information system of each branch. Because of the principle of data confidentiality, these systems can't provide a unified interface, which results in the system can't be maintained uniformly, and need to invest a large number of professionals and funds, among the application systems. It is difficult to connect and integrate application systems, which promotes the formation of information islands to a great extent[2], and makes it difficult for higher-level information processing, such as data mining, data integration, decision-making and other data acquisition, to have a significant impact.

The emergence of cloud computing has brought changes to the information construction of colleges and universities. By visiting the software library on the cloud of university information system established by cloud service providers, colleges and universities can get the required system applications without investing in the establishment of a complete set of internal software and procedures. The cost is relatively low. By using cloud computing platform, all kinds of resources distributed in different places are constructed virtually to realize resource sharing at the application level, so that colleges and universities can adapt to the changes of teaching situation in time, concentrate on improving teaching, promoting teaching management and improving classroom teaching efficiency[3]. 


\section{Basic concepts of cloud computing}

\subsection{Definition of cloud computing}

Cloud Computing is the development of Distributed Computing, Parallel Computing and Grid Computing, or the commercial implementation of these computer science concepts. "Cloud" is a computer group, each containing hundreds of thousands of computers, or even millions of computers. The basic principle of cloud computing is that computing is distributed on a large number of distributed computers, rather than in local computers or remote servers, and the operation of enterprise data centers will be more similar to that of the Internet. This enables enterprises to switch resources to applications they need and access computers and storage systems according to their needs[4].

\subsection{Characteristics of cloud computing}

Users in cloud computing do not own physical infrastructure as their own software platform. Instead, they avoid spending on IT fixed assets and lease resources from third-party suppliers. This resource is provided to customers as a service and charged to end users according to utility computing model, which is similar to power consumption in traditional utilities[5-6]. Multiple users share cloud computing capabilities, so that the server is not idle, can improve the speed of application development, while improving utilization and greatly reducing costs. This approach can also lead to a "significant increase in computer capacity", because cloud computing infrastructure can dynamically allocate idle resources to respond to customer requests, so that customers do not have to worry about the peak load of the server[7].

From the point of view of the existing cloud computing platform, compared with the traditional stand-alone and network application mode, its characteristics are shown in Table 1.

Table 1 Characteristics and specific process of cloud computing

\begin{tabular}{|l|l|}
\hline \multicolumn{1}{|c|}{$\begin{array}{c}\text { Technical } \\
\text { characteristics }\end{array}$} & \multicolumn{1}{c|}{ Specific processes and characteristics } \\
\hline Extremely cheap & $\begin{array}{l}\text { Because the special fault-tolerant measures of "cloud" can adopt extremely cheap } \\
\text { nodes to form the cloud, the automated centralized management of "cloud" makes a } \\
\text { large number of enterprises need not bear the increasingly high cost of data center } \\
\text { management, and the universality of "cloud" makes the utilization of resources greatly } \\
\text { improved compared with traditional systems, so users can fully enjoy "cloud". Cloud's } \\
\text { low-cost advantage often takes hundreds of dollars and days to complete tasks that } \\
\text { previously took tens of thousands of dollars and months to complete. }\end{array}$ \\
\hline Virtualization & $\begin{array}{l}\text { Cloud Computing supports users in any location, using a variety of terminals to obtain } \\
\text { application services. The requested resources come from "cloud" rather than fixed } \\
\text { tangible entities. The application runs somewhere in the cloud, but in fact the user } \\
\text { does not need to know or worry about the specific location of the application. With a } \\
\text { laptop or a mobile phone, we can use network services to achieve everything we need, } \\
\text { even tasks like supercomputing. }\end{array}$ \\
\hline High reliability & $\begin{array}{l}\text { "Cloud" uses such measures as data multi-copy fault tolerance, isomorphic and } \\
\text { interchangeable computing nodes to ensure high reliability of services. Cloud } \\
\text { computing is more reliable than local computers. }\end{array}$ \\
\hline On-demand services & $\begin{array}{l}\text { "Cloud" is a huge resource pool, you buy on demand; cloud can be charged like tap } \\
\text { water, electricity, gas. }\end{array}$ \\
\hline High scalability & $\begin{array}{l}\text { The scale of "cloud" can be dynamically retractable to meet the needs of application } \\
\text { and user scale growth. }\end{array}$ \\
\hline
\end{tabular}




\section{Application of cloud computing in university information construction}

Applying cloud computing technology to university information construction is actually a new mode of information resources application in Colleges and universities, which makes it very convenient and fast for schools to use network framework and application programs. However, due to the limitation of network size and resource coordination, cloud computing is mainly advocated and implemented by several large companies, and most of them are used for commercial purposes[8]. A few educational projects are just using the company's computing resources. If the existing cloud computing scheme is directly adopted, although the short-term cost is low and the implementation is simple, the transplantation of the original information system and the processing of the original computing capacity of universities will become the main problems[9]. So it will be a viable option to deploy cloud on the existing education network.

\subsection{Solution based on cloud computing mode}

1) Departments and branches of colleges and universities store the data they need on cloud databases, and use the unified data storage platform provided by cloud computing to manage and maintain data. This can reduce the cost of data maintenance and ease the need for database services due to the increase of data volume to a certain extent. The urgency of the expansion of the device and storage device[10].

2) Using PaaS and platform virtualization technology provided by cloud computing, we can ignore the choice of operation platform and development platform when developing MIS. Through browser, we can set up our own application, so that we can develop all kinds of management information systems with a unified information standard interface, avoiding the interface. The inconsistency results in poor information communication, which reduces the generation of information islands and enables the management to conduct unified task scheduling. At the same time, it also provides convenience for university management to conduct data analysis and decisionmaking.

3) Cloud computing provides all kinds of IT resources, including OS, servers, routers, memory and so on, to cloud consumers with virtualization technology as a service, as long as they pay on demand. Through cloud computing mode, colleges and universities no longer invest in infrastructure construction, only need to obtain virtual infrastructure services from cloud service providers according to their own needs, which greatly reduces the cost of construction, operation and maintenance of these infrastructure, while saving electricity[11].

Of course, in addition to the above technical solutions, we should pay full attention to the coordinated development of software system and hardware environment in the process of construction and implementation. Under the guidance of unified planning, the whole system construction should adopt unified standards and norms to build business application systems.

\subsection{Cloud Architecture}

The design and development of cloud services is a technology that must be mastered in the construction of university information. To build a comprehensive network application platform for university information construction, it should have the following characteristics: B/S structure, security, robustness, massive storage space, high-speed education MAN, relatively practical Web software. In view of the information construction in Colleges and universities, we should think of the functions shown in Fig. 1. 


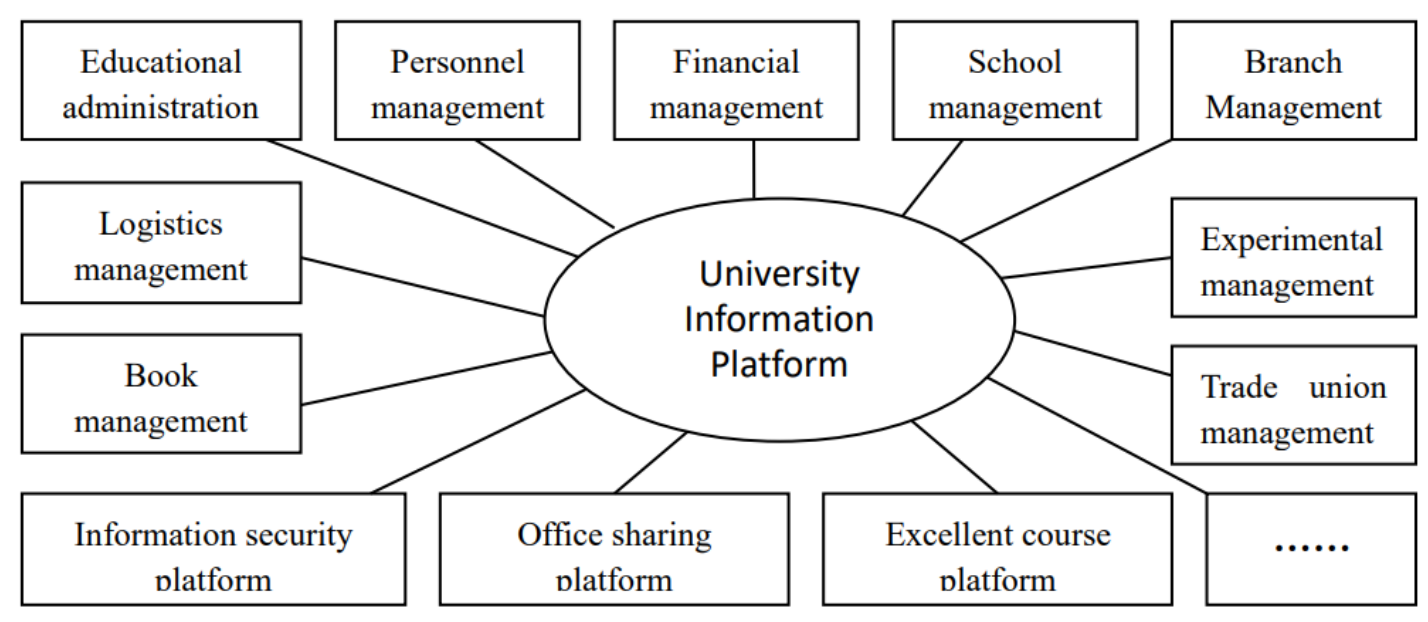

Figure 1. Function module

\subsection{Function development of teaching management system}

In the cloud computing environment, the existing teaching management system needs serviceoriented encapsulation or transformation, new computing and data centers providing basic application services, and cloud services supporting teaching information system, such as distance learning, virtual laboratory system, application server, etc.

The cloud service and data of the teaching management system will be studied, designed and developed by both the teaching designer and the system developer. The cloud service of the teaching management system can set up the following functional modules: teaching resource database, network examination database, teaching forum, teaching courseware development, experiment teaching, student status management, teaching quality evaluation, virtual classroom teaching, distance teaching, academic achievements and system management.

The system management module mainly completes the management of the system's basic code, system parameters, initial business data, system maintenance, system privileges and so on. In the development of cloud services, developers can use "loosely coupled mode" to develop various system modules of teaching information system. There are various kinds of sharing and cooperation among loosely coupled modes of various systems, but each system may only share data, or some way to own some of its own data. When information is released, all tasks need only one autonomous system to process. If an autonomous system can't process user requests, what loose coupling does is to transfer the requests to other autonomous systems for processing, so that the form of organizational structure can reflect the integrity of system functions and the independence of modules. It is conducive to the realization of the overall goal of teaching information system and the realization of its own interests. On this basis, developers can use relevant languages and frameworks to develop a variety of system applications that can be seamlessly used between loosely connected device networks, so that users can access teaching information system services and data through mobile devices such as Web browsers or mobile phones, so as to achieve maximum sharing. Avoid duplication of development.

\subsection{Problems of cloud existence}

Cloud computing has not yet unified standards and implementation methods. There are still many difficulties and problems in the construction of university information based on cloud computing. For example, there must be a large part of duplicate resources in the existing campus network. These 
resources should be fully utilized, then classified according to the institutions, or selected and concentrated. Add to the cloud; if data is stored in the cloud, the biggest problem is security and reliability; for example, for adding new application servers and virtual laboratories, it needs financial support; for example, the setting of virtual servers and access servers supporting cloud structure, and so on. Despite all kinds of problems and difficulties, cloud computing is the trend of the times, which will inevitably have a profound impact and change on the development of University information.

Besides providing computing services, cloud computing services also provide storage services. But cloud computing services are currently monopolized in the hands of private institutions (enterprises), which can only provide business credit. Government agencies and business organizations (especially those with sensitive data such as banks) should be vigilant enough to choose cloud computing services. Once commercial users use cloud computing services provided by private institutions on a large scale, no matter how strong their technological advantages, these private institutions will inevitably coerce the whole society with the importance of "data (information)".

For information society, "information" is very important. On the other hand, data in cloud computing is confidential for users other than data owners, but there is no secret for businesses providing cloud computing. It's like ordinary people can't listen to other people's phones, but within the telecommunications company, they can listen to any phone at any time. All these potential risks are an important prerequisite for business and government agencies to consider when choosing cloud computing services, especially those provided by foreign organizations.

\section{Conclusions}

Applying cloud computing to the construction of teaching information in Colleges and universities can not only integrate teaching information resources, improve the utilization rate of resources and improve teaching level, but also bring new application fields for cloud computing, make cloud computing services closer to our life and learning, and let us feel the tremendous impact of science and technology on us. Although the technology and scheme of realizing cloud computing network of university teaching information system is not mature enough, we have every reason to envisage the goal of sharing university information resources by utilizing cloud computing's efficient computing and processing capacity and unlimited storage capacity.

\section{Acknowledgment}

This work was sponsored by Qing Lan Project, supported by Research topics on teaching reform of higher education in Jiangsu Province 2017 (No. 2017JSJG348; Lead: Cuihua Sun), the education "13th Five-Year" Planning issues of Jiangsu province (No. B-b/2016/03/41; Lead: Cuihua Sun), and the modern educational technology research project of Jiangsu province (No. 2017-R-58821; Lead: Cuihua Sun).

\section{References}

[1] Information on https://go.juniper.net/cn/zh/Solution/A1_1.

[2] Information on https://baike.baidu.com/item/9969353?fr=aladdin.

[3] K. R. Yang and X. S. Hang, "Cloud Computing and The Solution of Information Construction Problem in Colleges and Universities”,Computer Knowledge and Technology, vol.5,No.20, pp. 5571-5573, July 2016.

[4] Information on https://cloud.tencent.com/developer/information.

[5] "Research and Implementation of High Performance Networking Platform over Cloud Computing”, COMPUTER ENGINEERING\& SCIENCE, vol.31,No., pp. 249-252, April 2016.

[6] Z. H. Ouyang, "Cloud computing and information integration”, Journal of Quanzhou Normal University 
(NATURAL SCIENCE), vol.3,No., pp. 38-43, July 2015.

[7] Information on http://www.yundaxue.org/home/cc/base.mooc..

[8] H. Ren, "Application of university teaching information system based on Cloud Computing", Academic discussion, vol.3,No.18, pp. 42-44, July 2017.

[9] M.D. Huang, "Thoughts on the Construction of Quality Standards for Student Cultivation in Chinese Universities, " Chinese University Teaching, vol. 4,No.3, pp.38-42, April 2017.

[10]Campbell R,et al.Open CirrusTM Cloud Computing Test-bed:Federated Data Centers for Open Source Systems andServices Research[C] // Proc of Workshop on Hot Topics in Cloud Computing,2009.

[11]LU Kai,CHI Wanqing,LIU Yongpeng,et al.HPVZ:A High Performance Virtual Computing Environment for Super Computers[C] // Proc of APPT ' 09, 2009. 